\title{
An Empirical Study of Nanowire Technological Trends
}

\author{
${ }^{1}$ Sercan Ozcan, ${ }^{2}$ Nazrul Islam \\ ${ }^{1}$ Portsmouth Business School, University of Portsmouth, Portsmouth, UK \\ sercan.ozcan@port.ac.uk \\ ${ }^{2}$ Business School, Exeter University, Exeter, UK \\ n.islam@exeter.ac.uk
}

\begin{abstract}
This paper follows a bibliometric method for a nanowire case to make evident the technological trends, to present the relationship between patents, to help the researchers to discover relatively significant patents, and to analyze important relationships between patents to identify those with most commercial potential and those which are critical technologies. This research focuses on a nanowire case study due to fact that this field is one of the most mature and has received the most investment in the study of nanotechnology. In terms of methodological approach, this study uses a different patent collection method than previous studies. This new method offers a new taxonomy that could make a significant impact on accurate patent data quests and increase the reliability of the patent analyses. Given that patent data are valuable sources of technology innovation and for forecasting technical change, this study utilizes nanowire patent documents to pick out the technological trends and to identify those nanowire technologies which have the most commercial potential and which are critical at the organizational, national and international levels.
\end{abstract}

Keywords: nanotechnology, patent analysis, bibliometrics, visualization mapping, nanowire

\section{Introduction}

Nanotechnology is defined as the manipulation and production of nanomaterials and nanodevices at the level of atomic and molecular precision (Ramsden 2005). Nanotechnology is interdisciplinary because it depends on the knowledge and expertise found in conventional disciplines, such as chemistry, physics, biology, material sciences, and medicine (Islam and Miyazaki 2009). Consequently, there is varied wide variety of research being conducted in order to gain insights into this field and to forecast its possible effects.

The focus of this study is nanowires and it aims to shed light on various technology trends and dominant actors by analyzing nanowire patents granted up until 2012. Nanowire is one of the most mature nanostructures that is available today and so an analysis of the patents in this field is significant because there are more applications for nanowires and the technology is closer to commercial exploitation. For this study, 4,484 nanowire patents have been analyzed and the data covers all of the patents granted until March 2012.

Patent data provide valuable sources of information for research in innovation and for forecasting technical change (Archibugi and Planta 1996). Reliable and valid information about a particular technology or innovation system can be gathered if the patent data is analyzed systematically (Choi and Park 2009, Lee et al. 2011). Some of the reasons why patent analyses are pursued include the discovery of promising technologies, assessment of technological advances and new trends, or to help in strategic decision-making for an organization (Firat et al. 2008). Patent analysis can benefit various individuals and organizations, such as inventors, $\mathrm{R} \& \mathrm{D}$ departments, policy-makers, academics, and managers. 
Generally, looking at various patent analyses, the most commonly used methods are bibliometric and statistical analysis; if some of these studies are clustered under various categories, then these can then be subjected to network analysis, citation analysis, trend extrapolation/impact analysis, life cycle analysis, innovation system modeling, road-mapping studies and economic base analysis (Kostoff et al. 2001, Wartburg et al. 2005, Daim et al. 2006, Miyazaki and Islam 2007, Chang et al. 2012).

This paper follows a bibliometric method to make the technological trends evident, to present the relationship between patents, to help researchers to discover relatively significant patents, and to analyze important relationships between patents to identify those with most commercial potential and those which are critical technologies. This paper analyses the nanowire case at the national and organizational context. The dominant actors, their intentions regarding nanowire technology usage and various nanowire applications are examined.

Although previous studies have used bibliometric studies to analyze patents and have focused on implementing nanotechnology related patent documents, these studies did not particularly focus on the nanowire case. In any event, there is a need for up-to-date studies in various areas of nanotechnology because it is an emerging field that is undergoing rapid development. Previous studies used a different methodology in terms of collecting patent documents and this paper increases the efficiency of nanotechnology patent analysis because a more reliable patent data collection method is used.

\section{An Overview of Nanowire Materials and Applications}

Nanowires (also known as quantum wires) are nanostructures that are less than tens of nanometres long. Silicon nanowires may provide the next architecture for transistor designs. Nanowire transistors can be at least four times faster than traditional silicon devices and this could provide high-performance, lowcost, flexible and miniaturized electronic circuitry for many products and applications.

Traditional materials are used in a wide range of applications, such as steel, plastic and ceramic. These types of materials were followed by more advanced materials, such as fibers, titanium and silicon, which offer different properties than traditional materials in terms of their mechanical, electrical or thermal properties (Harris 2009). These materials may shortly be replaced by some new materials, such as nanowires, due to their extraordinary characteristics, such as their conductivity level, rapid thermal response, or high flexibility. Nanowires are one of the next enabling materials that will reshape the future of various technologies, products, and systems. Figure 1 shows how material technology has changed over time. 


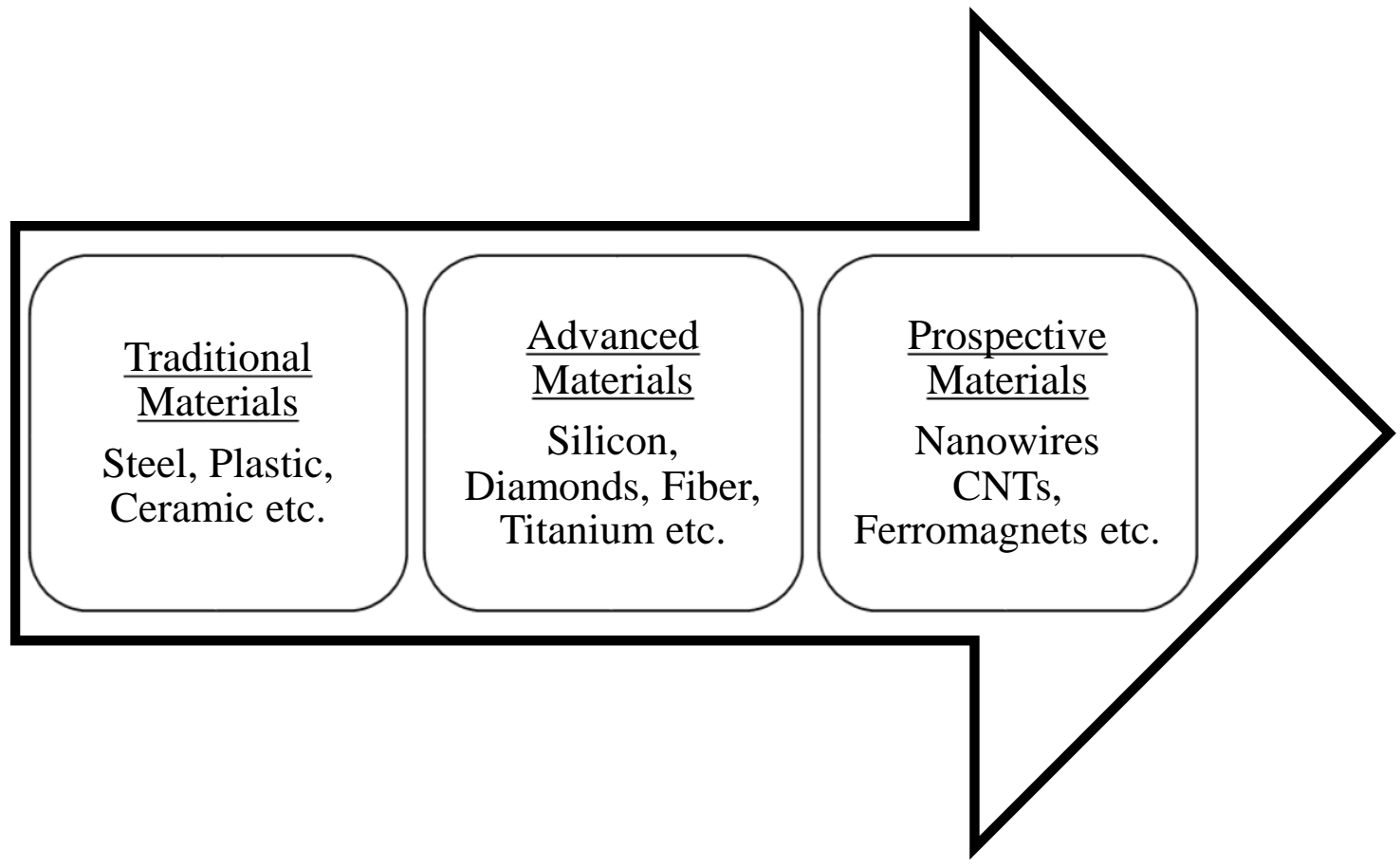

Figure 1: Advance of materials

Nanowires have many current and prospective applications in electronics, optics, magnetic and sensors (Dresselhaus et al. 2004). Some of these applications are at incremental and radical levels. Presently, there are very limited numbers of nanowire related applications and they are at an incremental level. However, there are significant numbers of potential applications and some of them are at radical level and, therefore, some technologies may change or be replaced by nanowire related advancements. Some of the potential applications of nanowires lie in magnetic information storage devices (Dresselhaus et al. 2004). By using nanowires, it is possible to increase the ability to store information in a smaller area and to suppress the onset of the superparamagnetic limit, which is important for avoiding magnetically recorded information.

There are many potential applications that are based on silicon nanowires (Shin 2007). Silicon nanowires can be designed to contour the transistor's channel, surrounded on all sides by a wrap-around silicon oxide, high-K metal gate. These new nanowire transistors will have different characteristics to the most improved FinFET transistors. For example, FinFET transistors have a three-dimensional gate (FinFET/Tri-Gate) while nanowires have a cylindrical shape so that the gate can be produced at many points all around the device. Nanosensors are another promising application that can be produced by nanowires. These new nanosensors are likely to be highly sensitive and they may be able to detect single molecules. Given that nanowires are at a very small scale, when molecules make contact with the nanowires they will generate a measurable change in the current passing through the nanowires. There are many possible applications for nanowires when used in nanosensors, one of their most important applications will be to detect cancer proteins. This would allow cancer tests to be more accurate and inexpensive.

Having mentioned the potential applications of nanowires, it is essential to mention that commercialization of nanowire related applications necessities reliable mass-production methods so that these new technologies can be transferred into industry. One of the biggest challenges in nanotechnology related studies is to identify and categorize possible applications because the field is 
generally highly diverse. This needs a deeper examination where the related technologies are categorized and the possible links between inventions and industry are drawn. For this purpose, patents are considered to be a great source to explore and identify key regions, organizations, and linkages for nanowires.

\section{Patent Examination and Tech Mining}

Patents have had a significant role in innovation and economic performance because of their pivotal role in the development of technology transactions (Archibugi Planta 1996 and Nelson 2009). The purpose of patents is to promote commercialization by authorizing inventors or organizations by law to profit from their inventions (Baldini 2006 and Grimaldi et al. 2011). Patents are regarded as an intersection between inventions and innovations, leading to the diffusion of technology. However, the common notion about the function of patents may not be true because they can hinder or support innovation depending on the circumstances (Fontana 2006, Motohashi and Muramatsu 2012). Consequently, the structure of patenting activity should be examined closely to understand the related determinants that affect this process.

Between 1985 and 2010, according to the WIPO database, almost 14 million patents were granted globally, and there was over $12 \%$ growth in 2010 (WIPO 2011). The growing use of patents for the purpose of securing inventions by corporate and academic organizations is related to changing patent regimes, innovation policies and large amounts of investment in R\&D (OECD 2004). Technological and scientific developments have created novel movements of innovation, particularly in nanotechnology. Patenting practices highly rely on collaborations between global networks of key actors across different systems of innovation. Meanwhile, the regulatory and legislative frameworks of patent systems have led to extensive domains of patentable subjects (Kang and Park 2012). For example, the patent classifications for nanotechnology were only introduced from 2004 (ETC Group 2005) and they are still in their development stage.

By exploring the changes in a particular patent data, it is possible to evaluate many aspects of technological change. Quantitative analysis on patents is used as measurement for the results of invention and innovation related activities. There are a large number of patent studies that focus on the association amongst technological advancement and economic progression (Greif 1992, Sorek 2011, Hidalgo et al. 2012). Meanwhile, some studies focus on the research and innovation developments in a countrywide and a global context (Abraham and Moitra 2001, Encaoua et al. 2006, Faber and Hesen 2004, Wu and Lee 2007). Some studies have concentrated on the viewpoint of corporate strategy to assess the stage of technology development in a particular sector by analyzing patent statistics (Bachmann 1998, Trappey et al. 2011, Tseng 2011). In some studies, the relationship between the key actors is analyzed within a particular innovation system through patent analysis (Waguespack and Birnir 2005, Tödtling et al. 2009, Dangelico et al. 2010).

Camerani and Malerba (2010) found that patent analysis can be used as one way to identify patterns in technological entry in different fields. They focused on examining the relationship between technological entries and patenting activities of different types of organizations and sectors. Traditional approaches explain that new entrants have mainly profit oriented motivations to become involved in a new field. In addition, previous studies have found that entry rates have a high correlation with the types of sectors and that high entry leads to better innovation performance (Geroski 1995). Camerani and Malerba (2010) identified that the share of new entrants significantly differs across different countries and sectors, and that a higher level of technological turbulence in one field leads to a lower level of repeated patenting by new entrants, and vice versa. Accordingly, examination of patent documents with 
regards to persistence development and continuity in the increasing number of new entrants may indicate the commercial potential of the field. Moreover, analysis of the distribution of number of patent documents may indicate the progress of the field because if the general distribution shows high number of patent ownership by individual organizations, then this may indicate lower turbulence and higher innovative potential.

Various studies have used bibliometric studies for patent documents and academic publications. In general, patent analysis by text-mining follows the general steps that are described by Tseng et al. (2007): 1) task identification by defining purpose of the study; 2) searching and retrieving patent data; 3) cleaning and categorization of the data by turning unstructured data to structured; 4) abstracting by summarizing the key sections of patent documents such as their claims, topics and patent codes; 5) clustering based on some extracted attributes; 6 ) visualization by various approaches such as heat maps; and, 7) interpretation to define trends, technological relations and also foresight of technological changes in the chosen field. Yoon and Park (2004) also followed a text-mining based bibliometric study on patent data sets and proposed a methodology that adds new network metrics compared to well know metrics (such as centrality, betweenness and closeness measures) to develop patent networks that are able to generate a deeper understanding of the results. Table 1 summarizes the previous studies where similar approaches and purposes have been used. 
Table 1: Methodological and application purpose of tech-mining and patent-mining studies (Porter and Cunningham 2005, Chiavetta and Porter 2013, Madani 2015, Ozcan and Islam 2017)

Bibliometrics

Scientometrics

Data mining

Text mining

Analytics,

Natural language processing and semantic analysis

techniques and

Information retrieval

methodological

approaches

Big data analysis

Network analyses

Co-occurrence, mapping, clustering analyses

Pattern recognition

Patent, publication and social media analyses

Data visualization

Emerging technologies and, technology dynamics and trends

Technology assessment, forecasting, road-mapping and foresight

Technological evolution, diffusion and convergence

Technology monitoring and business intelligence

Technology process management

Innovation analysis

Collaborative innovation, innovation cluster and network analysis

Purpose and application areas of studies
Absorptive capacity, dynamic capability and knowledge absorption levels

Social network analysis

Knowledge management

$\mathrm{R} \& \mathrm{D}$ and innovation management

Engineering and high-tech industries

Science and technology (S\&T) indicators

Science, technology and innovation policy studies

Evolutionary economics

Technology assessment and impact analysis

As shown in Table 1, application oriented focuses tend to be used, apart from methodological concerns in this field. Porter and Youtie (2009) looked at nanotechnology positions in relation to other disciplines by considering its multidisciplinary nature and addressed the cross-disciplinary linkages in this field. Another similar work was conducted by Miyazaki and Islam (2007), which focused on cross-country comparisons, actors and institutions by using similar quantitative methods (bibliometrics and tech mining) to understand the sectorial innovation systems in nanotechnology from a global perspective. Shapira et al. (2011) focused on an overview of corporate entry into nanotechnology through patents, publications, and nanotechnology innovation factors in the shift to commercialization. It is also observed that the influence of cross-border international invention links suggests that national 
innovation policies need to be open and international in orientation. Huang et al. (2003) also completed a similar work by presenting a longitudinal patent analysis of nanotechnology patents between 1976 and 2002. Their work included content map analysis and citation network analysis by obtaining the required data from individual countries, institutions, and technology fields.

The recent work of Song et al. (2017) focused on the development of new technology ideas by using a similar approach with f-term analysis. They found a systematic way to analyze how new technology ideas are generated by combining two technologies. This study was a great example of showing converging technologies and it may allow innovators to obtain new ideas by using their techniques. Similarly, Islam and Ozcan (2015) examined the technological links by using a tech-mining method to show how different applications and research areas merge together to create new technological domains. Similarly, Kay et al. (2015) studied another nanomaterial that is called graphene. In their study, they mapped the R\&D activities of graphene by using patent data with tech mining and data visualization approaches. They illustrated the landscapes of graphene science by mapping patent and publication data separately in the same time period to compare and understand the R\&D activities in this field. The authors then created overlays for graphene publication and patenting activities to show how graphene as a material was discovered and used between 2000 and 2013. As part of big data analytics, these types of studies are great way of examining and identifying technological activities in large data sets to give significant information to all actors (such as academia, industry and governmental bodies) so that they can make better and more informed decisions.

Having mentioned that patent analysis is relatively significant in various contexts, there are also various limitations to these studies. This is largely due to the fact that not all inventions lead to innovation and not every innovation has a fundamental influence on technological or economic value. In nanotechnology, there are many patented inventions that have not been commercialized. Therefore, it is not possible to claim that every nanotechnology related patent will be commercialized. Moreover nanotechnology is a highly dynamic emerging field. The progress of patents, innovations, and industry is rapidly changing and this causes even higher uncertainty. It is important to develop methodologies that can explain how patent activity collaborations occur and the interactions of dominant actors that shape this complex system. For this purpose, the methodology of this study offers a new taxonomy in gathering accurate patent data and analyzing them to answer the questions proposed.

An examination of the previous studies suggests that first of all there is a need for an up-to-date study in nanotechnology because it is an emerging field that is constantly changing. This study fulfils this need by analyzing all of the nanowire patent documents that are available until March 2012. Second, previous studies used a different methodology in terms of collecting patent documents and this paper increases the efficiency of nanotechnology patent analysis because a more reliable patent data collection method is used. Finally, the analysis of commercially promising sub-categories of nanotechnology also differentiates this study from previous studies.

Considering the topic, this study will use a tech mining method (Porter and Cunningham 2005) to test the following scenarios:

- Proposition 1: Nanowire related research is expected to have large differences across different regions, actors, and sectors due to its interdisciplinary nature and wide application.

- Proposition 2: Nanowire related technologies will have dominant actors in specific application areas due to repeated defensive patenting.

- Proposition 3: The distribution of numbers of nanowire patents amongst organizations and their relative density by large actors may indicate significant commercial possibilities. 
- Proposition 4: The patenting ratio between academic and industrial actors may indicate the stage of the field in terms of its research or commercial development.

\section{Methodology}

The present study applies a tech-mining methodology that was proposed by Porter and Cunningham (2005), which combines bibliometrics using patent abstracts from patent databases. Tech mining analyses the relations between actors and technologies within a given innovation system, using specialist keywords that are derived from the Nano Science and Technology Institute publications. The subsequent analysis was performed using the Thomson Data Analyzer (TDA) dedicated tech mining software, which allowed us to automate the mining and clustering of terms occurring in article abstracts and article descriptors (such as authors, affiliations or keywords) that are recommended by the Georgia Institute of Technology.

In addition to the patent analysis by TDA, Thomson Innovation's Themescape tool is also used. Themescape allows us to map the key terms for all of the available nanotechnology patents. Our analysis of a Themescape map was highly supportive for the findings of this study because it allowed the categorization of documents containing similar content as they were placed near each other on the map. Moreover, the density of documents can be indicated with tall or small peaks, and the distance between peaks sheds light on the relationship between content because peaks that are located closer to each other have more closely related content than peaks that are located farther away. Contour lines indicate relative document density and by using the tool it is possible to zoom in on a specific area whereby new contours, labels, and documents can be revealed. Accordingly, it becomes possible to explain various technological relationships under the umbrella of nanotechnology.

Various approaches are followed by patent analysts and researchers in this field. There are many limitations and drawbacks in terms of the search terms that are used and the nanotechnology patents which are obtained. There are two main approaches in this field. The first approach is to use all of the required nanotechnology related terms (such as nanotube, nanowire, and nanosensors) in the patent search and to try to get the highest possible hit list as a result. This type of search may be faced by two major problems. The first is that the researcher may not cover all of the required nano-terms and as a result they may not be able to access all of the required nanotechnology related patents. For example colloidal crystals, quantum dot, and fullerene do not include the term 'nano' but they involve nanotechnology related patents. Another issue with this type of research is that there are many patents that mention nanotechnology related materials within patent documents that are not for a nanotechnology invention. For example, if the details of some of the patents are analyzed, then it can be seen that the nanotechnology related term is used in the description of a non-nanotechnology patent that states the invention can also be used with one type of nanomaterials, such as nanotubes. As a result, it is possible to include unnecessary patents and exclude necessary patents in the analyzed patent data set.

The second common approach in nanotechnology related patent analysis is to obtain all of the patents that include terms that start with such terms as 'nano' or 'quantum' by using Boolean search logic such as nano* OR quantum* and excluding all of the unnecessary patents from the result which include terms such as nanosecond and nanometre. The problem with this approach is that there are many nanotechnology related patents that include these terms; for instance, there are many nanotechnology patents that include both 'nanowire' and 'nanosecond'. As was explained with the previous approach, there is also a possibility of obtaining unrelated patents that mention the possible compatibility of a particular nanomaterial or nanoparticle with the patented invention. 
Given the limitations and drawbacks of the above approaches, it was thought that the best nanotechnology search practice would be to use all of the available nanotechnology classifications to gather all the nanotechnology classified patents, such as 977 by USPTO, B82 by IPC, Y01N by ECLA and 3C082 by Japanese F-Terms. The irrelevant patents classified within these categories could be eliminated by using Boolean search logic with very broad nanotechnology related terms, such as 'nano*', 'quantum*' and 'fullerene*'. Afterwards, the DWPI (Derwent Patent Index) was used to exclude patents that appeared more than once in the search results because, due to nature of patent applications, inventions are granted more than once in various patent authorities to secure the invention in that respective country or region. For the nanowire case, the following search terms are used:

$(\mathrm{AIOE}=(\mathrm{B} 82 *)$ OR $\mathrm{FIC}=(\mathrm{B} 82 *)$ OR UCC $=(977 *))$ AND $\left(\mathrm{ALLD}=\left(\right.\right.$ nanowire* ${ }^{*}$ or nano-wire* or quantum ADJ wire* or nano ADJ wire*))

As a result 4484 individual nanotechnology patents were obtained for the period from 1970 to 2012 . The obtained results were imported into the TDA and, to validate results further, the duplicate results were eliminated and variations of company, inventor, and institute and university names were unified where they appeared as separate patent assignees. After the dataset was prepared, various functions were used with the same tool (i.e. TDA) to generate the required analysis.

\section{Analyses of Nanowire Patenting Trends}

There are 4484 patents related to nanowire technology. The patenting activity for nanowire technology started in 1994. There are 8420 inventors, 1619 organizations and 32 countries involved in this field. As shown in Figure 2, the peak year was in 2009 when 731 nanowire patent documents were filed. It appears that there has been a rapid increase in the number of nanowire patents starting from 1999 to 2010.

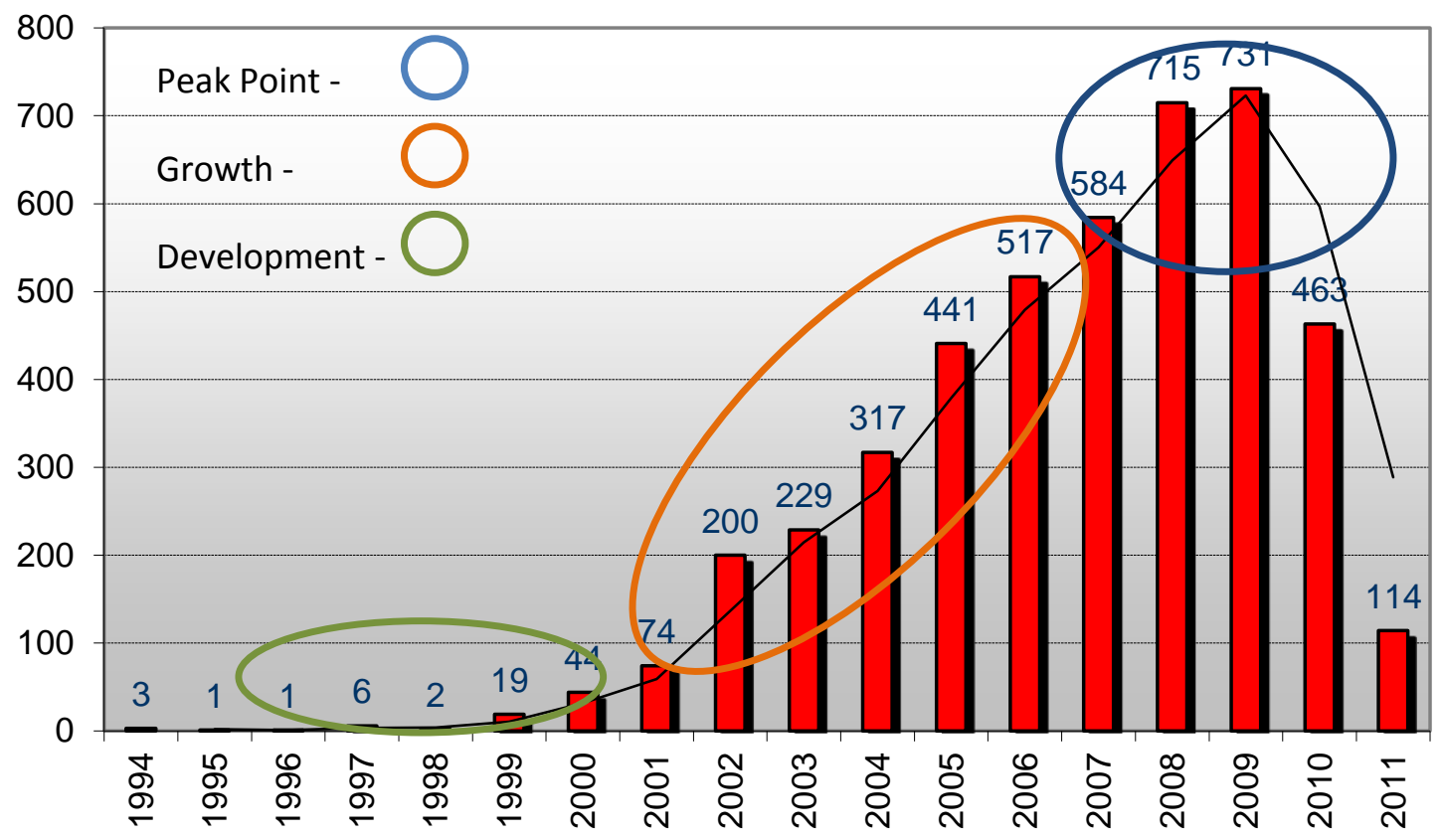

Figure 2: Number of nanowire records per Year 


\subsection{Technological Trends of Nanowire}

The highest numbers of nanowire patents are classified under the nanostructure devices that belong to organic semiconductor devices and thick/thin films (see Table 2). The primary attraction of organic molecular nanostructures is their potential low cost and the extreme flexibility that the device engineer has in choosing a material whose properties have been specifically tailored to meet the needs of a particular application. The materials are easily integrated with conventional semiconductor devices, thereby providing additional functionality to existing photonic circuits and components. Active organic nanostructures appear to be on the verge of transforming a large number of optical and electronic applications.

Another density of nanowire patents appears in the semiconductor nanomaterials that are expected to be one of the revolutionary materials for various industries. The current focus on nanomaterials is not only on the end structures, particles or materials themselves but also how to process them and how to produce them efficiently. The reason why companies focus on this area is because once the use of nanomaterials or nanostructures is increased and it becomes highly commercialized, mass production will be required and this is another problem that needs to be overcome by organizations before they can commercialize nanotechnology.

When the nanotechnology field is analyzed as a whole, it can be seen that polymer applications appear to be a key field for nanowires. There are many researchers working on nanowire-polymer nanocomposites and silver nanowire because these are the source of the materials that will allow companies to increase the efficiency of many electronic components and it will also make radical innovations possible. For example, a Portuguese company Displax has invented an electronic device that can interpret the electrical disturbances in a thin transparent polymer film that is embedded with nanowires. This innovative film can detect any type of pressure on it and it can identify it as a command. Accordingly, consumers can have a multi-touch interface anywhere because the thin film screen can be used on any non-conductive surface. These kinds of innovative products will usher in the commercialization of nanotechnology.

As shown in Figure 3, patenting activity for semiconductor nanowires starting from 2000 gradually increased and appears to have reached a peak in semiconductor nanomaterials. This is due to the patenting activity of large organizations within the electronics industry, such as Samsung, and IBM. The top nanowire patenting category that is related to thick/thin films and organic semiconductor devices (U12-B03F2) appears to have started to fall from 2005 (92 patent documents) to 2009 (11 patent documents). This may be due to progress and growing interest in carbon nanotubes because carbon nanotubes have very similar characteristics to nanowires and they can also be produced in different forms. Another reason for this decrease may be due to the fact that this sub-field of nanotechnology may have reached its peak where most of the possible inventions have already been made with regard to the applicability of nanowires. This could be a sign for the commercialization of nanowires for this particular area. Also, Proposition 1 appears to be wrong for the nanowire case because there are no large differences in nanowires due to the high concentration of the possible electronic applications. It is clear that there is less diffusion and multidisciplinarity in nanowire materials and technologies when compared to the nanotechnology. 
Table 2: Technology profile of nanowire

\begin{tabular}{|c|c|c|c|c|c|c|}
\hline 岂 & 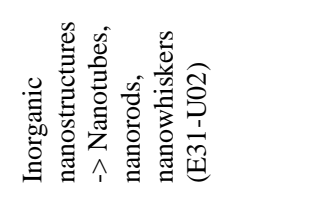 & 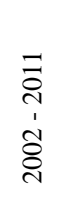 & 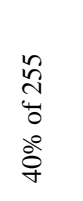 & 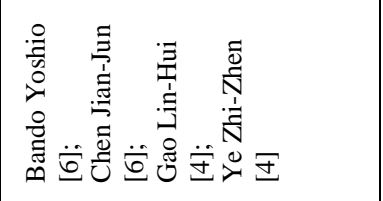 & 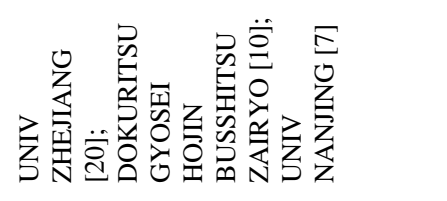 & 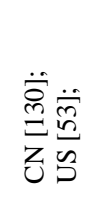 \\
\hline ه্ণ & 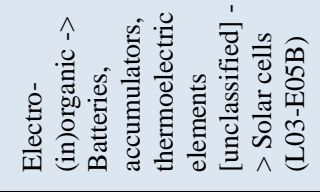 & 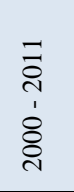 & 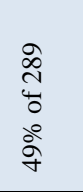 & 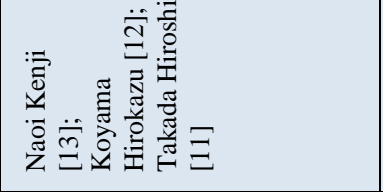 & 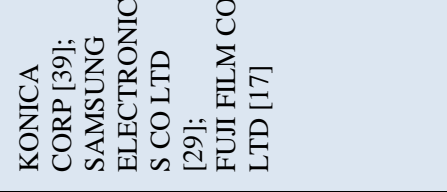 & 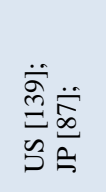 \\
\hline$\stackrel{\infty}{\infty}$ & 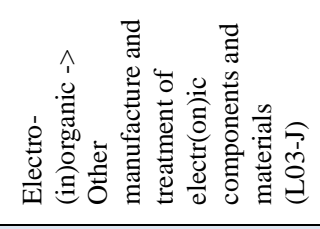 & 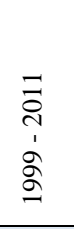 & 然 & 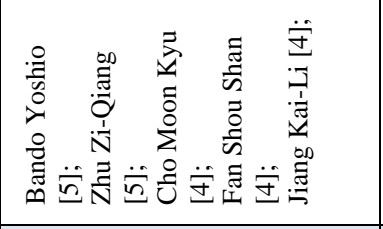 & 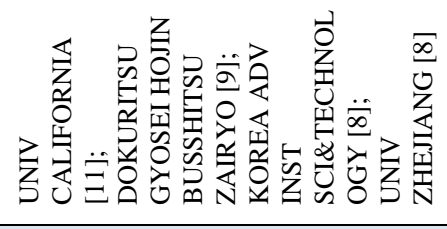 & 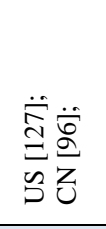 \\
\hline f & 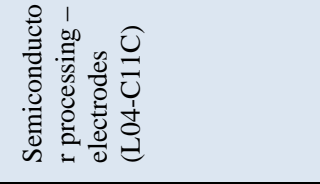 & 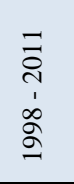 & 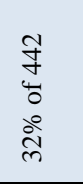 & 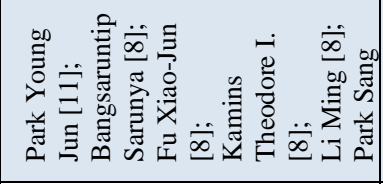 & 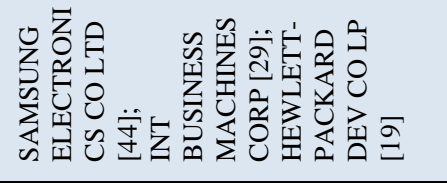 & 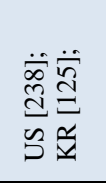 \\
\hline$\stackrel{m}{n}$ & 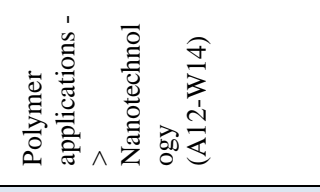 & 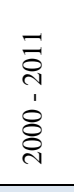 & $\begin{array}{l}\frac{m}{3} \\
\text { s. } \\
\text { ò } \\
\text { yे }\end{array}$ & 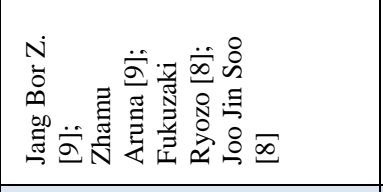 & 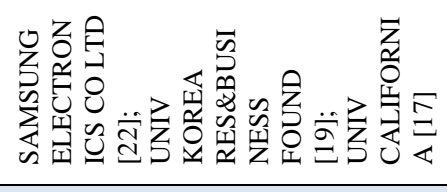 & 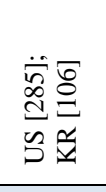 \\
\hline in & 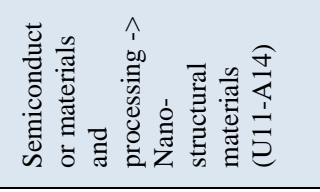 & 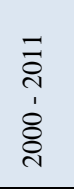 & 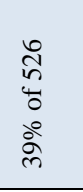 & 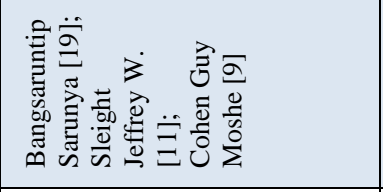 & 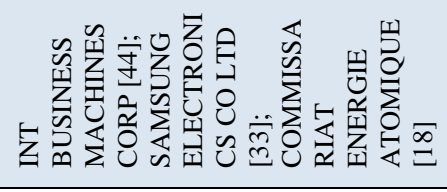 & 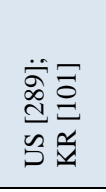 \\
\hline in & 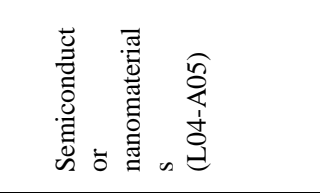 & $\begin{array}{l}\bar{T} \\
\text { ì } \\
\text { \&ें } \\
\end{array}$ & 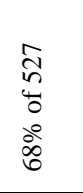 & 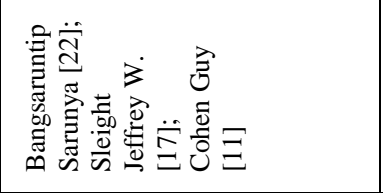 & 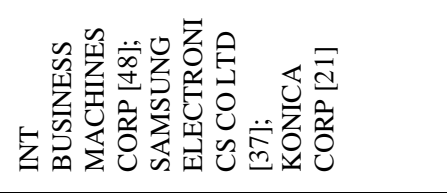 & 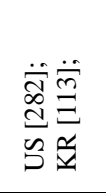 \\
\hline in & 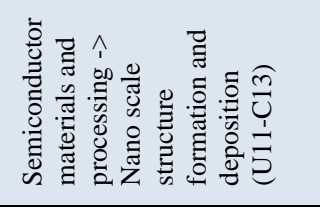 & 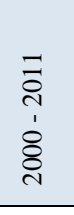 & 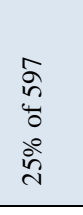 & 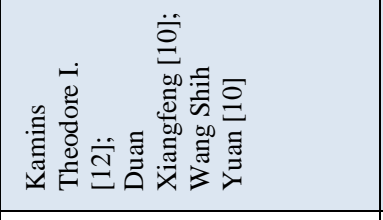 & 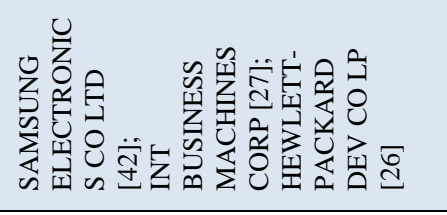 & 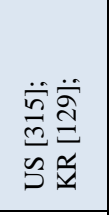 \\
\hline$\stackrel{n}{n}$ & 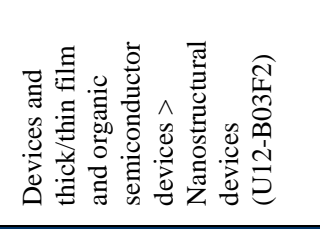 & 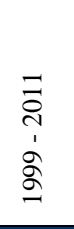 & 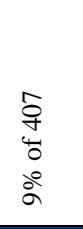 & 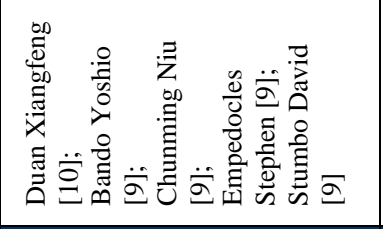 & 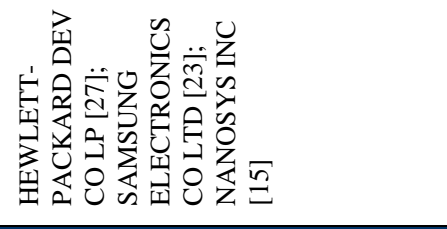 & 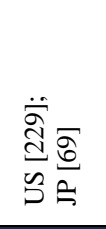 \\
\hline 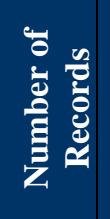 & 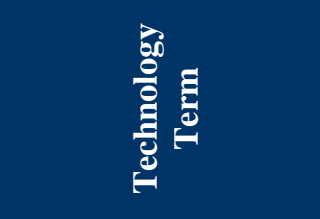 & 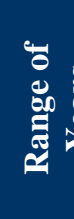 & 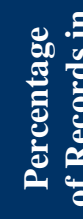 & 锫 & 竞 & 递 \\
\hline
\end{tabular}




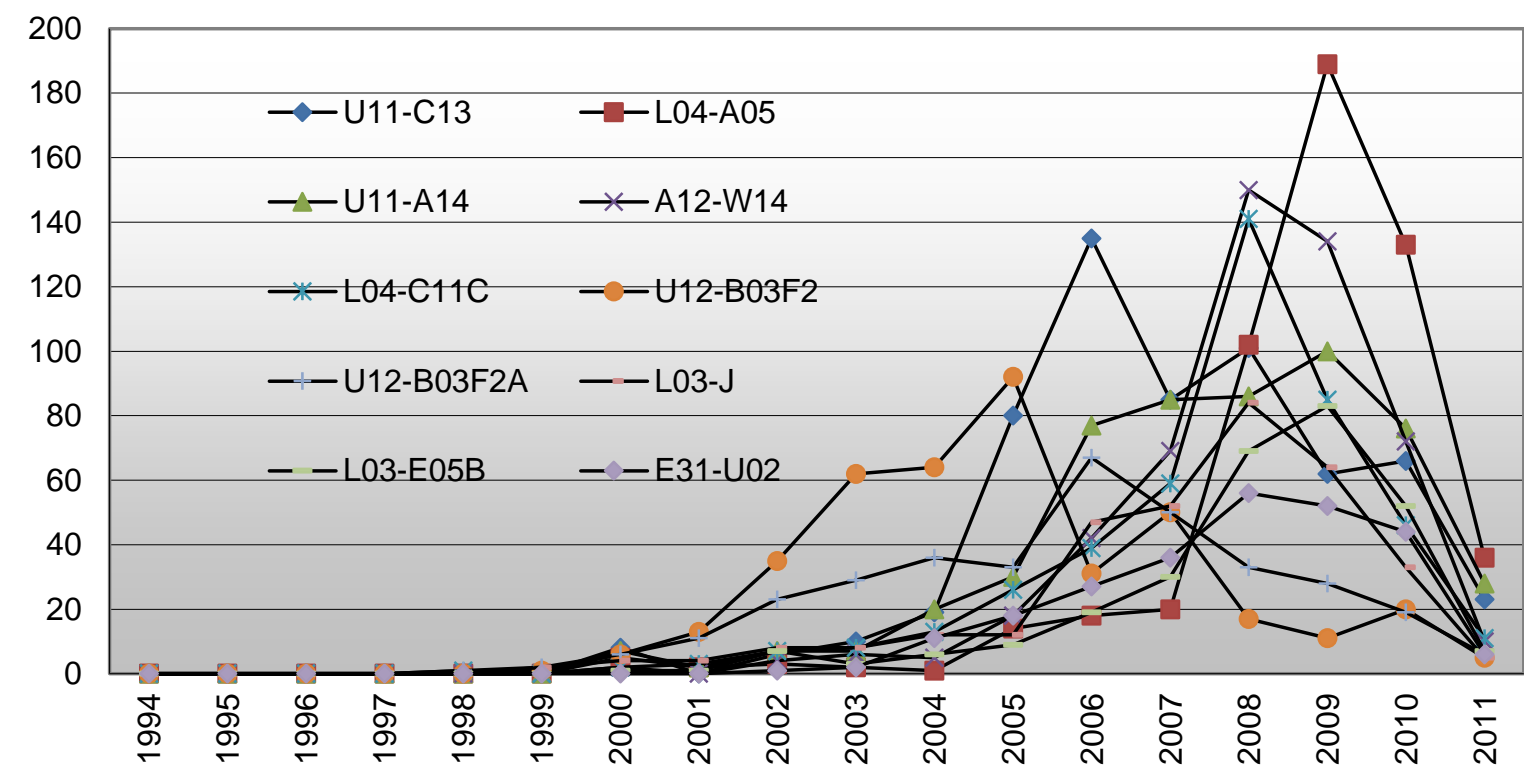

Figure 3: Technology trend for nanowire

\subsection{The Distribution of Nanowire Patents}

In Figure 4, the distribution of numbers of nanowire patents amongst organizations and their relative density within the area is presented. In general, it is accepted that mature fields have a higher number of patents, usually in the 100+ patent documents range. For instance, a field that is in its initial or development stage would have a higher proportion of granted patents, in up to the 20 documents range. As explained in the literature review, the commercial viability and profitability of a field encourages organizations to patent repeatedly. It seems that nanowire technology is at a stage between a developing and emerging technology because the number of patents that are granted to large organizations (101+ documents and 21-100 documents) is increasing but is not very significant if it is compared to the whole nanotechnology field and other mature technologies. The more nanowire patents that are granted to large organizations, the higher the possibility of commercial outcomes. Therefore, nanowire technology may be getting close to its highly commercialized stage, as stated in Proposition 3, based on its patenting distribution.

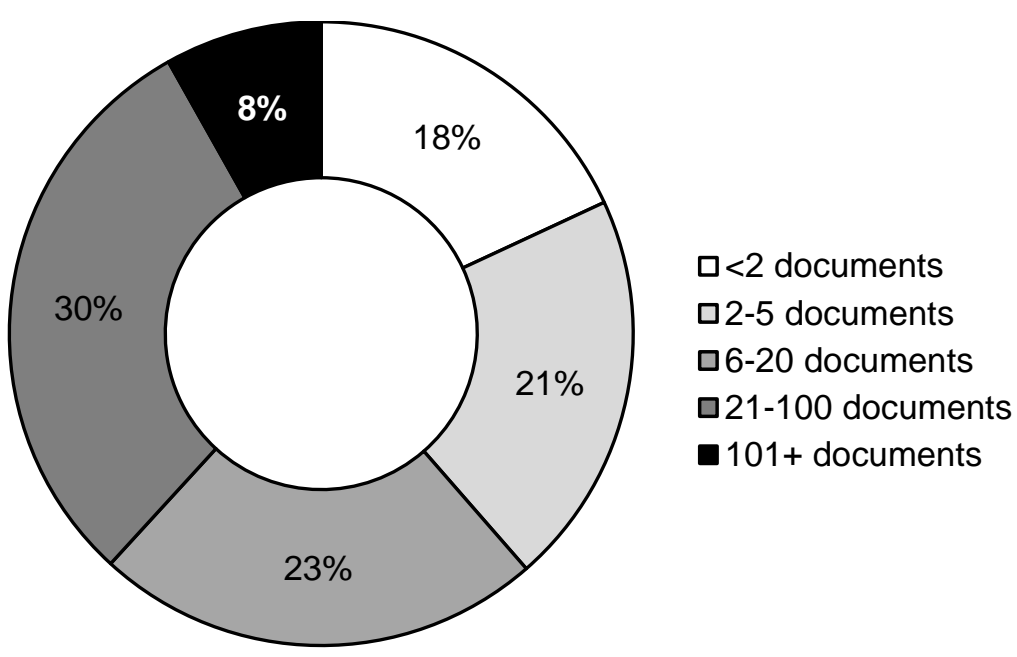

Figure 4: Distribution of nanowire patents by organization activity 


\subsection{Mapping of Key Nanowire Terms}

Figure 5 illustrates the mapping of key technology terms within nanowire patents. It appears that nanowires that act as insulators (e.g., $\mathrm{SiO} 2, \mathrm{TiO} 2)$ have the highest patenting activity, along with carbon nanotubes. The ability to insulate nanowires opens up new possibilities for nanoelectronics because insulation around the nanowires avoids different wires from shorting each other or conducting each other. Therefore, the nanowires can be used as the basis of coaxial cables or a simple gating configuration for the production of electronic devices such as transistors. From this point it can be gathered that nanowires can be used for very different purposes within the electronics industry given their possible different characteristics. Thus, researchers are trying to find a way to insulate nanowires so that they can be used as connectors for nanoelectronic components.

Another intense research area that is associated with a high number of patent documents and strong links with other nanowire technologies is the use of silver nanowires to prepare flexible, thin, transparent conducting films. At the very low thickness of nanowires, these new films act as networks and at the same time appear to be very transparent with optical transmittance, reaching as high as $92 \%$ for low thickness. Accordingly, silver nanowires have the potential to surpass the use of indium tin oxide in LCDs, touch screens, solar cells, and flexible displays. The technology challenges the use of carbon nanotubes because they have many characteristic advantages in various applications.

Looking at the peak point on the Themescape map (see Figure 5) of a catalyst-fuel-cell, which shows how often these words arose in nanowire patents, it is clear that nanowires have become an important structure, even in fuel use. Nanowires are used with new fuel cell catalyst systems to improve the performance of fuel cells. Nanowires form a metal alloy that is known as a bulk metallic glass, which has a high surface area so that more of the catalyst can be exposed and their activity maintained longer than in traditional fuel cell catalyst systems. This new process may fulfill future energy needs with high number of possible applications in automobiles, computers, and electronics equipment.

Degrees-cooling-surface is another peak point that indicates that there are a high number of nanowire patents that are concentrated in a specific field. The reason why these words appear among the most frequent is because this is one of the key methods by which nanowires are processed into some other form. The process is to heat a material in a furnace to an extremely high temperature above $1000{ }^{\circ} \mathrm{C}$ and then cool it down to around room temperature. It is possible to produce different nanoparticles and nanostructures, such as nanowires, by following various processes with the changes that take place at these high temperatures. For example, it is possible to change the size and structure of nanowires or produce nanowires from some other material. The reason why scientists are focusing on this process is because once the size and structure of a nanowire changes, then its characteristics change and so it is possible to use the resulting nanowires in different applications or it is possible to increase their efficiency. 


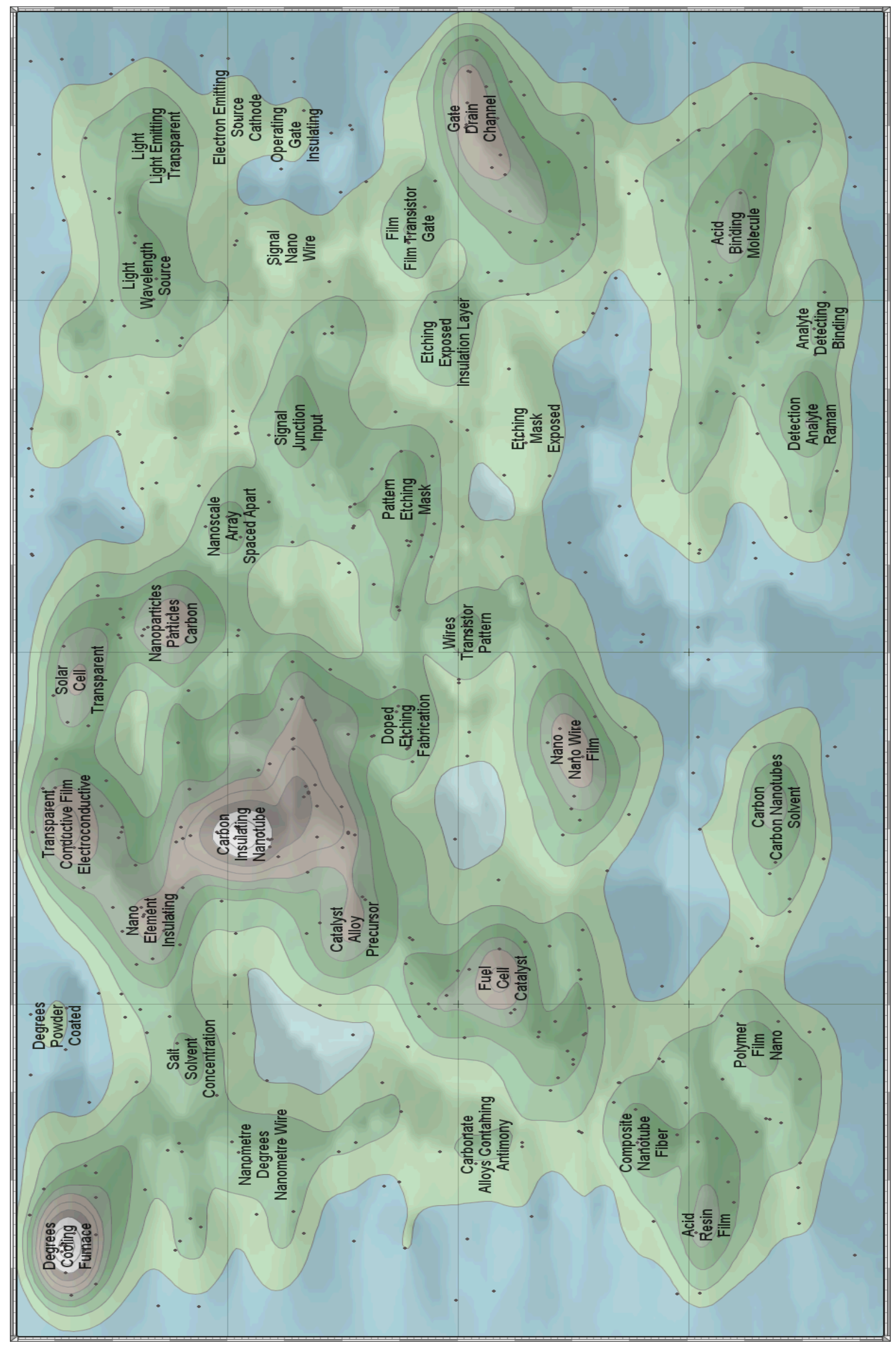

Figure 5: Themescape for the nanowire field 


\subsection{Organizational Involvement in Nanowire Patenting Activity}

The leading organizations in the nanowire field are Samsung, Hewlett-Packard, and IBM (see Table 3). All of the top companies, except Hewlett-Packard, have become involved in nanowire patenting activity after the millennium. IBM have been granted $54 \%$ of their nanowire patents within the last three years, which indicates their growing interest in this field in view of the applicability of this nanostructure in electronics. Table 3 shows that the key applicability of nanowires is in the electronics industry because the main patent holders in the field are the top players in that particular industry. The dominant countries for this technology with regard to top organizations appear to be the United States and South Korea. Examining Samsung's progress, it can be seen that Samsung's involvement in nanotechnology started with nanowire technology because, even though they are a newer player in nanotechnology compared to other companies such as IBM, only $17 \%$ of their nanowire patents have been granted within the last 3 years. As stated in Proposition 2, this field appeared to have dominant actors in specific application areas due to repeated defensive patenting. In particular, Samsung appears to have heavily prepared themselves for commercialization and future competition in this field. 
Table 3: Profile of nanowire organizations

\begin{tabular}{|c|c|c|c|c|c|}
\hline 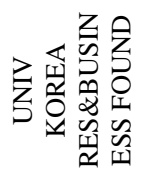 & $\stackrel{2}{2}$ & 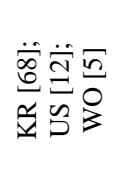 & 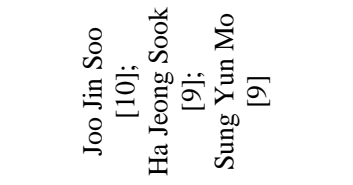 & 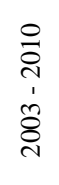 & 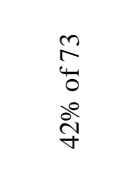 \\
\hline 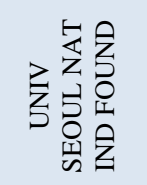 & $\approx$ & 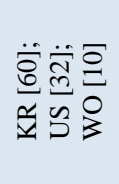 & 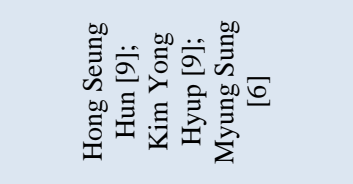 & 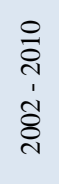 & 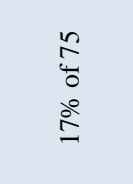 \\
\hline 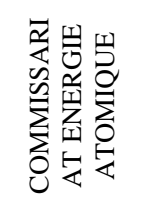 & 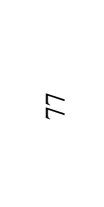 & 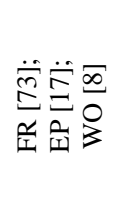 & 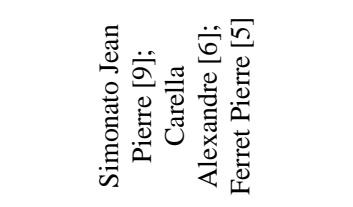 & 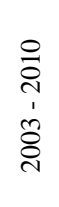 & 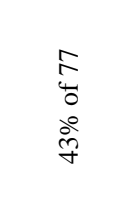 \\
\hline $\begin{array}{l}\infty \\
\bar{n}_{n} \\
0 \\
z_{z} \\
z\end{array}$ & $\stackrel{\infty}{\sim}$ & 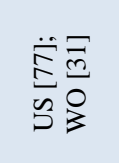 & 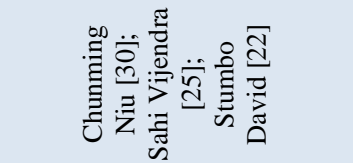 & 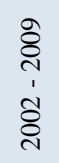 & $\begin{array}{l}\infty \\
\stackrel{0}{\circ} \\
\stackrel{0}{\sigma} \\
\dot{\sigma}\end{array}$ \\
\hline 荣壱 & 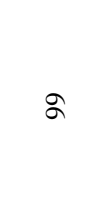 & 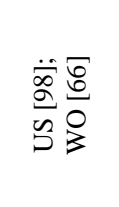 & 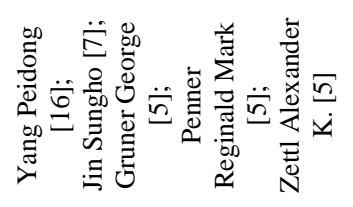 & 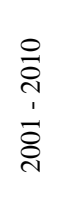 & $\begin{array}{l}2 \\
\dot{0} \\
\vdots \\
\infty \\
0\end{array}$ \\
\hline 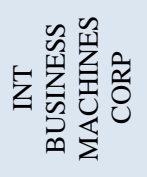 & $\nsubseteq$ & 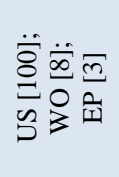 & 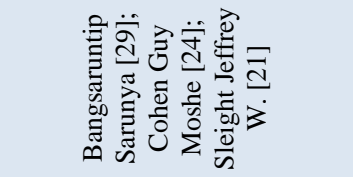 & 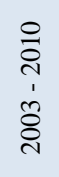 & 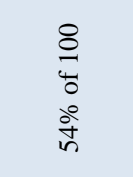 \\
\hline 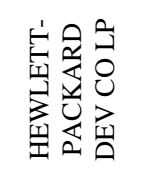 & $\stackrel{ \pm}{\stackrel{ \pm}{-}}$ & 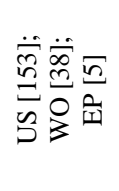 & 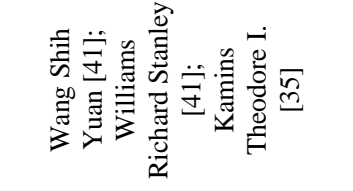 & $\begin{array}{l}\stackrel{0}{\circ} \\
\stackrel{2}{1} \\
\vdots \\
\text { ळे }\end{array}$ & 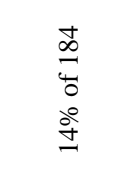 \\
\hline 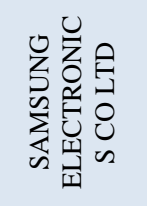 & \&్ల & 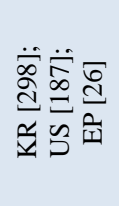 & 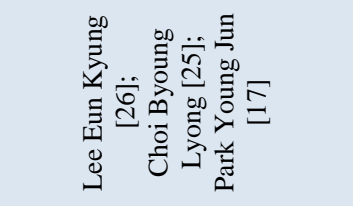 & 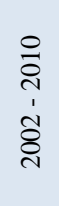 & 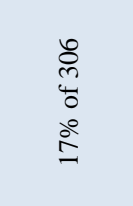 \\
\hline 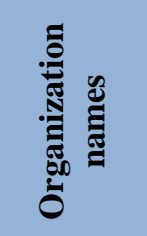 & 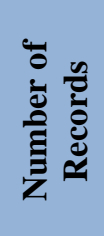 & 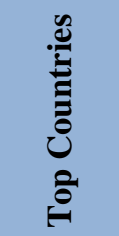 & 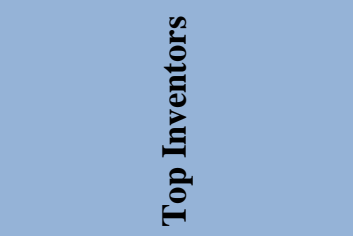 & 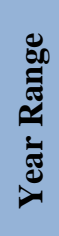 & 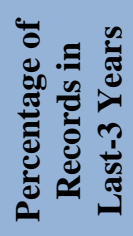 \\
\hline
\end{tabular}


The five largest actors in terms of patents use nanowires as a common nanostructure for various purposes. However, to understand the similarities in usage of this nanostructure among these organizations, the similarities in nanowire usage between any of two of the large organizations were calculated. The similarity matrix is based on the technology term items that the organizations have used in their patent documents. The scores are between 0 and 1, with 0 representing no similarity, and 1 representing total similarity. This matrix presents reasonable evidence that almost $50 \%$ of patents that are owned by the top five organizations are similar in terms of technology terms used. The greatest similarity in nanowire technology terms was found to be between HP, Samsung, and Nanosys. The similarities among nanowire patents granted to these giant organizations are due to two main reasons. First, there is a huge amount of collaboration and a number of strategic alliances between these organizations. IBM and Samsung collaborate under the Common Platform Technology and they have made a unique contribution to the semiconductor manufacturing process. This collaboration allows various other organizations to create compatibility between their manufacturing facilities and processes in terms of production of various materials at different nano levels, such as $32 \mathrm{~nm}, 45 \mathrm{~nm}, 65 \mathrm{~nm}$, and $90 \mathrm{~nm}$. Accordingly, there is considerable closeness in terms of technology terms used because there are common goals between IBM and Samsung while they have also heavily invested in research and patents. The second and the most obvious reason is the fact that these five top organizations are all heavily involved in the same industry and so their research focus is similar. Another important fact that stands out is the closeness of nanowire patent terms between the University of California and Nanosys, with a similarity value of 0.577 . This is due to their co-owned patents and their collaboration in the nanotechnology field (as shown in brackets, there are two co-owned patents). In contrast, there are some cases where the similarity matrix appears very low, as in the example of IBM and the University of California. The low similarity value may be due to the unique technologies that they own (see Table 4)

Table 4: Company similarity matrix

\begin{tabular}{|c|c|c|c|c|}
\cline { 2 - 4 } \multicolumn{1}{c|}{} & NANOSYS & $\begin{array}{c}\text { CALIFORNIA } \\
\text { UNIV }\end{array}$ & IBM & HP \\
\hline SAMSUNG & $0.587(0)$ & $0.415(0)$ & $0.567(0)$ & $0.614(1)$ \\
\hline HP & $0.601(0)$ & $0.421(0)$ & $0.473(0)$ & \multicolumn{2}{c}{} \\
\hline IBM & $0.419(0)$ & $0.261(0)$ & \multicolumn{2}{c}{} \\
\cline { 1 - 4 } CALIFORNIA UNIV & $0.577(2)$ & \multicolumn{2}{c|}{}
\end{tabular}

Note: The numbers in brackets presents the number of co-owned patents.

In Table 5, the patent codes with unique technology terms are listed for each company within the nanowire field. The total number of unique patent codes can be identified next to the organization's name. It should be clarified that although the number of unique patent codes appears to be more than the actual number of patents for each organization, this is due to the fact that each patent is actually classified under a number of related patent codes. For example, HP owns 184 nanowire patent documents in total (as shown in Table 3) but in the Table 5 it appears that they have 187 unique patent codes.

All of Samsung's nanowire patents were assigned with 394 unique patent codes that are linked to the various technologies within the electronics industry. Even though Samsung's patents have high similarity values in terms of technology terms that are used, Samsung is still the leading company in terms of having the highest number of unique patents. For example, Samsung is the only company that uses nanowire supported catalysts for fuel cell electrodes (X16-E06A5A is classified as a catalyst in electric power engineering). The aim behind Samsung's 20 patents related to this technology is to effectively use platinum in fuel cells as an electrocatalyst and to improve their durability. 
As mentioned previously, there is a lower similarity value between the University of California and other organizations. Table 5 proves that this is due to high number of unique patent codes that they own, in total there are 255 unique nanowire patents. The uniqueness of the technology terms that are used for specific patents shows the novelty of these inventions, which may represent a new application of nanotechnology in a particular field. In addition, larger numbers of unique technology terms show the technological strength of first movers and the way that they diffuse nanotechnology in various fields. Having said that, IBM appears to have the lowest number of unique technology terms, which may be due to the fact that they focus on incremental innovation by trying to develop further what is already in existence or it may be due to the fact that other organizations have started learning from IBM and have became involved in similar fields

Table 5: The patent codes, with unique technology terms for each organization

\begin{tabular}{|c|c|c|c|c|}
\hline SAMSUNG (394) & HP (187) & IBM (62) & $\begin{array}{l}\text { CALIFORNIA } \\
\text { UNIV (255) }\end{array}$ & NANOSYS (175) \\
\hline X16-E06A5A [20] & S03-E04D1 [10] & U11-C08A6 [8] & B04-F11 [8] & T04-K01B [7] \\
\hline L03-E04B1 [19] & U21-B01T [7] & U11-C08A5 [6] & A12-W11L [7] & U14-K01A3 [5] \\
\hline L03-C02A [13] & U21-B05E [7] & L04-C17 [2] & B05-C07 [4] & U11-C19B [5] \\
\hline U12-A02A4A [12] & T01-S03 [6] & E31-M [2] & B06-F03 [4] & D09-C04B [3] \\
\hline T04-F02A2 [9] & U21-C01T [5] & A12-E07C1 [2] & B04-E08 [4] & B05-A03A5 [3] \\
\hline T04-F02C [9] & L03-G04A [4] & U11-C05B3 [2] & B05-U03 [3] & B12-K04A [2] \\
\hline X16-E06A1 [8] & V07-F01A [4] & U12-D02A4 [2] & B04-F10 [3] & V04-X01B1 [2] \\
\hline V05-A01A3 [8] & U21-C01E [4] & E10-A19B [2] & L03-G10A [3] & U11-C15A [2] \\
\hline A12-E15 [8] & J04-B01A2 [4] & L04-C11C3 [2] & B04-C03B [3] & V01-B03A1 [2] \\
\hline V05-D05C5 [8] & T04-G02C [3] & U12-A02A2 [2] & D05-H08 [3] & W02-G05A [2] \\
\hline
\end{tabular}

In Tables 6 and 7 the industrial and academic involvement in nanowires can be seen based on their unique and shared capabilities. In Table 6, the "academically held nanowire technologies" section shows the academic actors have unique and diverse capabilities across different fields such as material science, chemistry, and medical technologies. Industrial actors have electronics sector oriented focus using nanowire structures (as explained in previous sections). Table 6 also shows that the use of nanowires in inks, ink-jet technologies, and photodiodes are key areas where they focus. Looking at very recent academic work, it can be seen that academia also focuses on the applications of nanowires in this field. For example, Duke University scientists found that "nanowire inks" enable paper based printable electronics to be produced by suspending tiny metal nanoparticles in liquids (Stewart et al. 2016). This new invention allows us to print inexpensive, customizable circuit patterns on just about any surface. Table 7 shows the concentration areas where both academic and industrial actors have common patenting categories. As expected, many of these fields appear to be related to electronics. Table 8 shows recent fields where nanowire related patenting trend occurs by looking at new patenting areas in this field where it has not been done before. To produce this result, nanowire patent data is analyzed in time domain by checking the date when a patent code appeared for the first time using the nanowire term in the patent document. For example, it can be seen that nanowires were being used in manual input devices such as touch screen devices from 2010 onwards. Other emerging technology areas can be seen from 2007 to 2011 in Table 8 . 
Table 6: Industrial and academic involvement in nanowires

\begin{tabular}{|c|c|}
\hline Industrially held nanowire technologies & Academically held nanowire technologies \\
\hline $\begin{array}{l}\text { U14-K01 A2B - Three terminal switching } \\
\text { elements of LCD [16] }\end{array}$ & $\begin{array}{l}\text { L04-C06B - Semiconductor processing - resists } \\
\text { [12] }\end{array}$ \\
\hline U14-K01A1C - LCD optical components [11] & A10-D - Condensation polymerisation [4] \\
\hline U11-C05G1B - capacitor manufacture [10] & $\begin{array}{l}\text { B06-F03 - Heterocyclic fused ring with } 2 \text { rings - } \\
\text { sole heteros S and N [5] }\end{array}$ \\
\hline $\begin{array}{l}\text { U12-B03C - organic devices that are related to } \\
\text { electronic applications.[8] }\end{array}$ & $\begin{array}{l}\text { E05-U01 - Fullerene type cage structures } \\
\text { containing hetero atom(s) [4] }\end{array}$ \\
\hline $\begin{array}{c}\text { A08-D01 - Crosslinkers and accelerators for } \\
\text { other polymers [8] }\end{array}$ & E11-M - Fermentation - processes, apparatus [3] \\
\hline $\begin{array}{l}\text { T04-G02J - Applications of ink-jet printing } \\
\text { technology [8] }\end{array}$ & $\begin{array}{l}\text { E31-B03C - Non-metallic elements, metalloids } \\
\text { and compounds (F, BR, I compound) [6] }\end{array}$ \\
\hline $\begin{array}{l}\text { U12-A01A1 - Semiconductor structure of } \\
\text { individual LED [8] }\end{array}$ & S03-E03E - Electrophoresis [4] \\
\hline $\begin{array}{c}\text { U21-B01T - Electronic switching or gating, } \\
\text { characterised by switching device (using } \\
\text { nanotubes) [8] }\end{array}$ & S05-Y03 - Implantable medical devices [4] \\
\hline L04-E02A - Photodiodes [7] & $\begin{array}{l}\text { A11-B02A forming processes - } \\
\text { orienting/stretching film [4] }\end{array}$ \\
\hline T04-G02C - Ink [7] & B03-L Vitamins [5] \\
\hline
\end{tabular}


Table 7: Shared patent codes by academia and industry

\begin{tabular}{|c|}
\hline Patent codes that are shared by academia and industry \\
\hline U12-B03A - Thin/thick film transistors (inorganic) [49] \\
\hline U11-C01B - Chemical vapour deposition of semiconductor layer [39] \\
\hline U11-A13 - Precursors for deposition process in semiconductor manufacture [30] \\
\hline U11-C07B Wet-etching for semiconductor manufacturing [31] \\
\hline J04-C04A - Gas sensors [29] \\
\hline X12-D01D - Nanomaterials under cables, conductors, conductive materials [28] \\
\hline L04-C16A - Annealing in heat treatment of semiconductors [29] \\
\hline U12-A02A4A - Solar cell electrodes [25] \\
\hline U11-C03J2A - Annealing semiconductor layer [25] \\
\hline A05-J12 - Polypyrroles and polythiophenes [25] \\
\hline
\end{tabular}

Table 8: Emerging nanowire technologies

\begin{tabular}{|l|l|}
\hline Year & New technology terms \\
\hline 2007 & $\begin{array}{l}\text { L04-C20B - Encapsulation of semi-conductor device using glass or other compositions [4 } \\
\text { of 12]; } \\
\text { U11-C02J3 - Doping non-semiconductor layers, insulators, polymers [3 of 10]; } \\
\text { V07-F02A - Lenses; reflectors; refractors [3 of 9]; } \\
\text { U11-A05B - Substrate materials [3 of 3]; } \\
\text { V05-D05C - Cathodes [3 of 3]; } \\
\text { S03-C06 - Detecting presence of person or object [3 of 3]; } \\
\text { W04-M01P - Power supplies [3 of 3] }\end{array}$ \\
\hline 2008 & $\begin{array}{l}\text { L04-A03D - Zinc oxide in a semiconductor material AII-BVI CPDS [5 of 39] } \\
\text { X15-A02C - Solar / photovoltaic panel details [6 of 18]; } \\
\text { L03-H04E5 - Ceramic substrates for PCB [5 of 9]; }\end{array}$ \\
\hline 2009 & $\begin{array}{l}\text { L03-E05B1 - Dye-sensitized solar cells [4 of 9]; } \\
\text { A12-W15 - Controlled release [4 of 4]; } \\
\text { U13-A01A - IC radiation sensor with photodiode, photoconductor [4 of 4] }\end{array}$ \\
\hline 2010 & $\begin{array}{l}\text { W01-C01B8H - Manual input devices based on absolute position, including touch screen } \\
\text { [11 of 13]; } \\
\text { L04-C12J - Gate insulating layers [3 of 4]; } \\
\text { M25-C02 - Dry reduction of ore to metal - methods [3 of 3]; } \\
\text { X15-A05 - Large scale solar power generation [3 of 3]; } \\
\text { X21-B04 - Combination of battery and other source [3 of 3] }\end{array}$ \\
\hline 2011 & L04-C07G - Photoetching [2 of 2] \\
\hline
\end{tabular}




\section{Discussions and Conclusions}

In this article, nanowire patent documents were carefully analyzed with four foci, which are international, organizational, technological, and institutional profiles. In addition, this paper explored different models within innovation system theory, and various network and cluster models were examined to form the theoretical basis of the study.

The international profile of nanowire technology provided valuable information, such as key regions, with regard to the number of nanowire patents. This research has also presented country based key technology domains and dominant players within those countries. An interesting outcome was to see the changing trend of countries' involvement in nanowire technology because Asian players in the last year had a huge involvement in this area. It appears that South Korea and China are now ahead of Japan and are close to the United States in terms of the number of nanowire patent documents granted.

With respect to the key actors within the nanowire case, it was found that within the electronics industry the ownership of patents is mostly dominated by large organizations. There are two main reasons why there is considerable heterogeneity in nanowire patenting activity. First, large organizations have the capability to provide the huge investment necessary for R\&D activities and they are aware of the benefits of nanowire technology in terms of its efficiency and its incremental innovative characteristics. Second, they collaborate with academic organizations, such as universities and institutions, to benefit from their inventions. The second point is not found in every national innovation system, but South Korea, the United States, and Japan appear to have a more effective environment compared to other nations.

This paper also looked at the key emerging technologies that can be gathered from nanowire patents. There are three different areas identified that have the greatest potential for commercialization. The highest level of patenting activity in the nanowire field was related to insulators. For example, it was shown that nanowires can be insulated in a way so that they can be used as nano level coaxial cables or as a simple gating configuration for the production of electronic devices such as transistors. Another important nanowire patenting field was related to silver nanowires that are used to prepare flexible, thin, transparent conducting films. This may be the base for future technology for transparent displays, flexible devices, and highly efficient electronic equipment.

To summarize the important implications of this study, the following conclusions are listed:

- Nanowire technologies and materials are found to be in high concentration in their possible applications in electronics.

- There is less diffusion and multidisciplinarity in nanowire materials and technologies when compared to nanotechnology.

- Nanowire related technologies have different focus application areas where they are controlled by some dominant actors with a high number of patenting activities and this acts as a barrier to other actors.

- The distribution of the numbers of patents and their relative density by large firms indicated high commercial possibilities in the near future.

- The majority of patent ownership by industrial actors indicated that this field is closer to commercialization.

- In terms of country based activities, Asian organizations, especially in South Korea and China, appear to be having a great impact in nanowires and this may have many commercial outputs in the near future. 
- There is a sector concentration in nanowires (mainly in the electronics industry). However, the key capabilities of each country and various organizations were identified and the applications of nanowire technology are very varied.

- Key potential technologies in the nanowire case include semiconductor technology and active or potentially active organizations should become involved in this field to gain a competitive advantage.

To take this study further, there are many other relationships that can be looked at within nanowire technology. As was mentioned in the findings section, there are some organizations and inventors who hold a large number of nanowire patent documents but the question is whether they are highly influential patents in terms of citations, commercial potential and quality. Accordingly, a follow-up study could be conducted on nanowire patent documents to look at this field in terms of quality in comparison with quantity using citation analysis. 


\section{References}

Abraham B. A. \& Moitra S. D. (2001) Innovation assessment through patent analysis. Technovation, $21(4), 245-252$.

Archibugi D. \& Planta M. (1996) Measuring technological change through patents and innovation surveys. Technovation, 16(9), 451-468.

Bachmann A. (1998) Profiles of corporate technological capabilities: A comparison of large British and German pharmaceutical companies. Technovation, 18(10), 593-604.

Baldini N., Grimaldi R. \& Sobrero, M. (2006) Institutional changes and the commercialization of academic knowledge: A study of Italian universities' patenting activities between 1965 and 2002 . Research Policy, 35(4), 518-532.

Camerani, R. \& Malerba, F. (2010) Patterns of technological entry in different fields: an analysis of patent data.

Chang K., Chen D. \& Huang M. (2012) The relationships between the patent performance and corporation performance. Journal of Informetrics, 6(1), 131-139

Chiavetta, D. \& Porter, A. (2013) Tech mining for innovation management. Technology Analysis \& Strategic Management, 25(6), 617-618.

Choi C., \& Park Y., 2009. Monitoring the organic structure of technology based on the patent development paths, Technological Forecasting and Social Change, Volume 76, Issue 6, Pages 754-768.

Daim T. U., Rueda G., Martin H. \& Gerdsri P. (2006) Forecasting emerging technologies: Use of bibliometrics and patent analysis. Technological Forecasting and Social Change, 73(8), 981-1012.

Dangelico R. M., Garavelli A. C. \& Petruzzelli A. M. (2010) A system dynamics model to analyze technology districts' evolution in a knowledge-based perspective. Technovation, 30(2), 142-153.

Dresselhaus M.S., Lin Y. M., Rabin O., Black M. R. \& Dresselhaus G. (2004) Nanowires, Springer Handbook of Nanotechnology, 99-145.

Encaoua D., Guellec D. \& Martínez C. (2006) Patent systems for encouraging innovation: Lessons from economic analysis. Research Policy, 35(9), 1423-1440.

ETC Group (2005) Nanotech's "Second Nature" Patents: Implications for the Global South. Winnipeg, Manitoba: Action Group on Erosion, Technology and Concentration.

Faber J. \& Hesen A. B. (2004) Innovation capabilities of European nations: Cross-national analyses of patents and sales of product innovations. Research Policy, 33(2), 193-207.

Firat A. K., Woon W. L. \& Madnick S. (2008) Technological Forecasting: A Review. Cambridge, MA: Massachusetts Institute of Technology.

FontanaR., Geuna A. \& Matt M. (2006) Factors affecting university-industry R\& D projects: The importance of searching, screening and signaling. Research Policy, 35(2), 309-323. 
Geroski, P. A. (1995) What do we know about entry? International Journal of Industrial Organization, 13(4), 421-440.

Greif S. (1992) Patents and sectors of economy. Connection between the international patent classification and the systematics of the sectors of economy. World Patent Information, 14(4), 245-249.

Grimaldi R., Kenney M., Siegel D. S. \& Wright M. (2011) 30 years after Bayh-Dole: Reassessing academic entrepreneurship. Research Policy, 40(8), 1045-1057.

Harris P. (2009) Carbon Nanotube Science: Synthesis, Properties and Applications. Cambridge: Cambridge University Press.

Hidalgo A., Molero J. \& Penas G. (2010) Technology and industrialization at the take-off of the Spanish economy: New evidence based on patents. World Patent Information, 32(1), 53-61.

Huang, Z., Chen, H., Yip, A., Ng, G., Guo, F., Chen, Z. K., \& Roco, M. C. (2003). Longitudinal patent analysis for nanoscale science and engineering: Country, institution and technology field. Journal of Nanoparticle Research, 5(3-4), 333-363.

Islam N. \& Miyazaki K. (2009) Nanotechnology innovation system: Understanding hidden dynamics of nanoscience fusion trajectories. Technological Forecasting and Social Change, 76(1), 128-140.

Islam, N. \& Ozcan, S. (2015) The management of nanotechnology: analysis of technology linkages and the regional nanotechnology competencies. R\&D Management.

Kang K. \& Park H. (2012) Influence of government R\&D support and inter-firm collaborations on innovation in Korean biotechnology SMEs. Technovation, 32(1), 68-78.

Kay, L., Porter, A. L., Youtie, J., Rafols, I. \& Newman, N. (2015) Mapping graphene science and development: Focused research with multiple application areas. Bulletin of the American Society for Information Science and Technology, 41(2), 22-25.

Kostoff R. N., Toothman D. R., Eberhart H. J. \& Humenik J. A. (2001) Text mining using database tomography and bibliometrics: A review. Technological Forecasting and Social Change, 68(3), 223 253.

Lee C., Jeon J. \& Park Y. (2011) Monitoring trends of technological changes based on the dynamic patent lattice: A modified formal concept analysis approach. Technological Forecasting and Social Change, 78(4), 690-702.

Madani, F. (2015) 'Technology Mining' bibliometrics analysis: applying network analysis and cluster analysis. Scientometrics, 105(1), 323-335.

Miyazaki K. \& Islam N. (2007) Nanotechnology systems of innovation: An analysis of industry and academia research activities. Technovation, 27(11), 661-675.

Motohashi K. \& Muramatsu S. (2012) Examining the university industry collaboration policy in Japan: Patent analysis, Technology in Society. 
Nelson A. J. (2009) Measuring knowledge spillovers: What patents, licenses and publications reveal about innovation diffusion. Research Policy, 38(6), 994-1005.

OECD (2004) Patents and Innovation: Trends and Policy Challenges. Available on: http://www.oecd.org/dataoecd/48/12/24508541.pdf

Ozcan, S. \& Islam, N. (2017) Patent information retrieval: approaching a method and analysing nanotechnology patent collaborations. Scientometrics, 1-30.

Porter A. L. \& Cunningham S. W. (2005) Tech mining: exploiting new technologies for competitive advantage. New Jersey: John Wiley and Sons.

Porter, A. L. \& Youtie, J. (2009) How interdisciplinary is nanotechnology? Journal of Nanoparticle Research, 11(5), 1023-1041.

Ramsden J. J. (2005) What is Nanotechnology? Nanotechnology Percetions.

Shapira P., Youtie J., Kay L., (2011). National innovation systems and the globalization of nanotechnology innovation. The Journal of Technology Transfer. 36, 587-604.

Shin M. (2007) Efficient Simulation of Silicon Nanowire Field Effect Transistors and Their Scaling Behaviour. Journal of Applied Physics, 101.

Song, K., Kim, K. S. \& Lee, S. (2017) Discovering new technology opportunities based on patents: Text-mining and F-term analysis. Technovation.

Sorek G. (2011) Patents and quality growth in OLG economy. Journal of Macroeconomics, 33(4), 690699.

Stewart, I. E., Kim, M. J. \& Wiley, B. J. (2016) The Effect of Morphology on the Electrical Resistivity of Silver Nanostructure Films. ACS Applied Materials \& Interfaces.

Tödtling F., Lehner P. \& Kaufmann A. (2009) Do different types of innovation rely on specific kinds of knowledge interactions? Technovation, 29(1), 59-71.

Trappey C. V., Wu H., Taghaboni-Dutta F. \& Trappey J. C. (2011) Using patent data for technology forecasting: China RFID patent analysis. Advanced Engineering Informatics, 25(1), 53-64.

Tseng F., Hsieh C., Peng Y. \& Chu Y. (2011) Using patent data to analyze trends and the technological strategies of the amorphous silicon thin-film solar cell industry. Technological Forecasting and Social Change, 78(2), 332-345.

Tseng, Y. H., Lin, C. J. \& Lin, Y. I. (2007) Text mining techniques for patent analysis. Information Processing \& Management, 43(5), 1216-1247.

Waguespack D. M. \& Birnir J. K. (2005) Foreignness and the diffusion of ideas, Journal of Engineering and Technology Management, Volume 22, Issues 1-2, Pages 31-50.

Wartburg I., Teichert T. \& Rost K. (2005) Inventive progress measured by multi-stage patent citation analysis. Research Policy, 34(10), 1591-1607. 
WIPO, Economics and Statistics Division (2011). World Intellectual Property Indicators. Available on: http://www.wipo.int/ipstats/en/statistics/patents/

Wu Y. J. \& Lee P. (2007) The use of patent analysis in assessing ITS innovations: US, Europe and Japan. Transportation Research Part A: Policy and Practice, 41(6), 568-586.

Yoon B. \& Park, Y. (2004) A text-mining-based patent network: Analytical tool for high-technology trend. The Journal of High Technology Management Research, 15(1), 37-50. 